\title{
Gendered Pathways to Integration: Why Immigrants' Naming Practices Differ by the Child's Gender
}

\author{
Jürgen Gerhards · Julia Tuppat
}

Received: 20 December 2019 / Accepted: 2 November 2020 / Published online: 30 November 2020 (C) The Author(s) 2020

\begin{abstract}
We analyze gender differences in immigrants' ethnic boundary making using the example of name giving. We draw on the well-established finding that immigrants are more likely to choose a name that is common in the host country (strategy of boundary crossing) for female than for male descendants. We distinguish between two dimensions that help us to understand the gender gap in naming: the impact of origin-specific factors (institutionalization of gender equality in the country of origin and religious affiliation) and immigrants' level of integration into the host country. Using data from the German Socio-Economic Panel Study on immigrants from 49 countries, we show that both sets of factors have a strong impact on immigrants' boundary making in naming, as well as on the extent of the difference between daughters and sons: traditional gender role attitudes foster the gender gap in naming, whereas integration into the host country reduces it.
\end{abstract}

Keywords Symbolic boundaries · Boundary making · Assimilation · Gender differences · First names

J. Gerhards $(\bowtie) \cdot$ J. Tuppat

Institut für Soziologie, Freie Universität Berlin

Garystraße 55, 14195 Berlin, Germany

E-Mail: j.gerhards@fu-berlin.de

J. Tuppat

E-Mail: julia.tuppat@fu-berlin.de 


\section{Geschlechtsspezifische Integrationspfade: Warum sich die Vornamenvergabepraktiken von Migrantinnen und Migranten für Jungen- und Mädchennamen unterscheiden}

Zusammenfassung Wir analysieren geschlechtsspezifische Unterschiede in der symbolischen Grenzarbeit von Migrantinnen und Migranten am Beispiel der Vornamenvergabe für Töchter und Söhne. Unser Beitrag stützt sich auf den bereits etablierten Befund, dass Migrantinnen und Migranten für weibliche Nachkommen eher einen im Aufnahmeland gebräuchlichen Namen wählen (boundary crossing) als für männliche. Wir unterschieden zwei Dimensionen, um diesen geschlechtsspezifischen Unterschied bei der Namensvergabe zu erklären: die Auswirkung von herkunftsspezifischen Faktoren (Grad der Geschlechtergleichheit im Herkunftsland sowie Religionszugehörigkeit) und den Integrationsgrad der Migrantinnen und Migranten im Zielland. Mit Daten des Sozio-oekonomischen Panels (SOEP) zeigen wir an einem Sample von Migrantinnen und Migranten aus 49 verschiedenen Herkunftsländern, dass beide Dimensionen einen starken Einfluss auf die symbolische Grenzarbeit bei der Namensvergabe, sowie insbesondere auf das Ausmaß des Geschlechterunterschieds haben: Der Unterschied in der Namensvergabe zwischen Töchtern und Söhnen ist umso stärker ausgeprägt, je traditioneller die im Herkunftsland vorherrschenden Geschlechterrollenbilder sind, während er sich mit steigendem Integrationsgrad im Zielland verringert.

Schlüsselwörter Symbolische Grenzen · Grenzarbeit · Assimilation · Geschlechterunterschiede · Vornamen

\section{Introduction}

People who migrate from one country to another usually face a multitude of changes in their lives, ranging from learning a new language to adapting to new institutional settings, such as the education system, labor market, or politics, to less codified contexts of daily life, such as dress codes, food consumption, or religious practice. These differences between home country and host country are often referred to as symbolic boundaries (Alba and Nee 2005; Lamont and Bail 2008; Wimmer 2008). By changing their country of residence, immigrants have to adapt to the new social environment and the perceived symbolic boundaries in the host country.

This also applies when immigrants give birth to a child in the host country and come to decide on a name. First names work as markers of social identity, as they usually reveal information about the person's gender, sometimes even about their social class, and also about their ethnic origin (Lieberson and Mikelson 1995; Lieberson et al. 2000; Sue and Telles 2007). If we meet someone called Eylül or Pavlov, we infer from the first name that the person is likely to have a migration background. ${ }^{1}$ Thus, if parents choose a name that is common in their country of

\footnotetext{
${ }^{1}$ The assignment of a first name to a specific social group is mainly based on the empirical distribution of first names in different social groups.
} 
origin, they mark their child's ethnic origin, whereas if they choose a name that is common in the host country instead, they assimilate into the majority society and disguise their child's ethnic origin. The first case can be described as a strategy of boundary maintenance, whereas the second strategy may be termed boundary crossing (Horowitz 1975; Zolberg and Woon 1999; Lamont and Bail 2008; Wimmer 2008). Name giving is a suitable indicator for studying ethnic boundary making as it reflects more than a mere intention or attitude, as it is the result of an actual choice that is restricted by very few regulations. ${ }^{2}$

Owing to the signal function of first names and the reactions of the majority society to these signals, the parents' decision has consequences for the child: several, mostly experimental, studies have shown that immigrants with foreign names are discriminated against, for instance, in the labor or housing market, regardless of their skills or resources (Bertrand and Mullainathan 2004; Fryer and Levitt 2004; Widner and Chicoine 2011; Kaas and Manger 2012; Blommaert et al. 2014; Auspurg et al. 2017; Schneider et al. 2014; Horr et al. 2018).

Various studies have tried to explain why some immigrants decide on boundary crossing, whereas others choose boundary maintenance. Results indicate that the likelihood of boundary crossing is larger, the smaller the cultural distance between home and host country and the better immigrants are integrated in the host society socially in terms of friendships or intermarriage and structurally in terms of education, occupation, and citizenship (Watkins and London 1994; Lieberson 2000; Gerhards and Hans 2009). ${ }^{3}$ At the same time, some studies have identified gender differences in naming (Lieberson 2000; Sue and Telles 2007; Becker 2009): they all find that parents choose boundary crossing significantly more often for their daughters' first names, whereas they are more likely to stick to boundary maintenance when naming sons.

Several theoretical explanations for the gender gap in naming are discussed in the literature. (1) It is suggested that the gender difference in naming reflects traditional gender role attitudes: male descendants are seen as the representatives of family tradition and ethnic origin, and therefore more often receive names that are common in the country of origin. For female descendants, parents are more willing to assimilate into the host country in their naming practices. (2) A rather instrumental explanation suggested by Sue and Telles (2007, p. 1411) is that parents feel a stronger need to protect girls from ethnic discrimination than boys, and are therefore more likely to choose assimilated names for daughters than for sons. We suggest that

\footnotetext{
2 Compared with other countries, the naming process in Germany is rather restrictive. Although not regulated by law, certain naming guidelines apply. For instance, a first name must be recognizable as such; it may not be an object or a widely used place or brand name. Furthermore, a first name must indicate the gender of the child. Although it has been possible to choose a gender-neutral first name since 2008, it must be accompanied by a further name that clearly identifies the sex of the child. A first name must not hamper the wellbeing of the child, for instance by having a connection to "the evil." First names may be rejected by the registry office if they do not comply with the regulations.

3 However, these associations do not exist in all groups (Alba 1990). For instance, Lieberson and Mikelson (1995) have shown that the emergence of the "Black Consciousness Movement" has led to a revival of African American names, accompanied by a re-ethnicization. In his typology of ethnic boundary making, Andreas Wimmer (2008) describes the attempt to re-evaluate symbolic boundaries by enhancing one's own group and by devaluating the majority society as transvaluation or inversion.
} 
this mechanism might also reflect specific gender roles, as girls are perceived to be more vulnerable and in need of protection. (3) An alternative explanation shifts the focus from the child to the parent. Sue and Telles argue that mothers may be more influential when it comes to daughters' names, whereas fathers have the greater impact on the name choice for sons. ${ }^{4}$ Some studies indicate that female immigrants assimilate at a faster rate into the host country than males (Rumbaut 1994; Feliciano and Rumbaut 2005). Hence, if mothers choose girls' names, while fathers choose boys' names, higher rates of boundary crossing in name choice for daughters may go back to the fact that mothers are better integrated in the host country than fathers. However, empirical evidence for both a female advantage in integration (Haug 2003) and for gender-specific patterns in decision power in naming is inconsistent or deficient. (4) Finally, Lieberson (2000) discusses the relevance of linguistic preferences with regard to girls' and boys' names. By analyzing naming practices of Mexican immigrants in the USA, he shows that the phonetic features in Mexican and USAmerican names are more similar in girls' than in boys' names; consequently, girls receive names that are common in the host country more often than boys. Following this example, the prescribed gender gap in naming may be a side effect of differences in linguistic similarities between boys' and girls' names of the name pools of the host and home countries and thus may occur regardless of the parents' genderrelated attitudes.

In this article, we use these studies as a starting point, but expand the existing literature. First, seeking to explain the gender gap in naming, we differentiate between explanations related to immigrants' context of origin on the one hand and to their level of integration in the host country on the other hand. Previous studies have investigated only one immigrant group; hence, they were not able to analyze the impact of the context of origin on gender differences in naming systematically. Our sample consists of immigrants from 49 countries, which provides us with sufficient variation in specific features of the context of origin and thus, enables us to analyze their impact on immigrants' naming practices. We assume that immigrants' gender role attitudes affect the gender gap in naming and that individual gender role attitudes are strongly influenced by the gender role regime in the home country. We suggest that the stronger the principle of gender equality is institutionalized in the country of origin, the smaller the differences in immigrants' naming practices in the destination country between girls and boys might be.

Second, previous studies indicate that the level of integration into the destination country impacts naming practices of immigrants. Integration is accompanied with greater exposure to the culture of the destination country and should increase the likelihood of boundary crossing in naming for both daughters and sons. However, most previous studies did not systematically analyze different dimensions of integration, but focused on a few aspects only. Our data enable us to consider several facets

\footnotetext{
4 To our knowledge, this assumption is not supported empirically. The specified references Alford (1987) and Herbert (1999) in Sue and Telles (2007, p. 1411) do not yield sufficient empirical evidence on an interaction effect between the gender of the parents and the gender of the child in name giving.
} 
of integration simultaneously: structural and social integration, as well as emotional identification with the host country. ${ }^{5}$

Analyzing immigrants' boundary work in the naming of sons versus daughters helps us to understand the gendered process of integration of the second generation of immigrants. Using first names as an indicator to measure processes of boundary crossing has certain advantages. As Stanley Lieberson (2000) argued, compared with other markers of boundary crossing names are not associated with material costs. Furthermore, first names are free and available to all parents. Hence, the selection of a first name is an expression of the parents' preferences, unrestricted by material and institutional constraints, and can be interpreted as a pure expression of the desired degree of boundary crossing or boundary maintenance respectively.

\section{Naming Practices and the Child's Gender}

In line with the findings of previous studies, we assume that immigrants more often choose names that are common in the host country for girls than for boys (Watkins and London 1994; Lieberson 2000; Sue and Telles 2007; Becker 2009). To explain this phenomenon, we investigate several factors that can be assigned to two broader explanatory dimensions: we assume that the parents' decision is shaped by (1) specific features of the context of origin and (2) immigrants' level of integration into the host society.

\subsection{Features of the Context of Origin}

Immigrants bring along a set of values and moral concepts to the host country (Luthra et al. 2018). We hypothesize that the values immigrants acquired in their home country will continue to be important during their lives in the host society. We assume that immigrants' values can contribute to explaining gender differences in naming practices. Based on the literature, we suggest that gender role attitudes are important predictors of gender differences in naming and that they are shaped by the institutionalization of gender equality and religion in the context of origin.

\subsubsection{Gender Roles in the Country of Origin}

There are two ideal types of gender role models: The first, traditional model is the socalled Breadwinner Model (also Male-Breadwinner-Female-Homemaker Model). It describes a nuclear family with a distinct division of labor between the two-usually married-spouses: women are mainly responsible for child rearing and housework, whereas men are single income earners (Dorbritz 2017, p. 80), and usually have dominance over the family. The second, egalitarian model has developed because

\footnotetext{
5 Furthermore, we are able to take up Lieberson's argument about the linguistic overlap between the country of origin and the host country, which is larger for female than for male first names in our empirical analyses. For this, we assign our respondents' countries of origin to groups based on linguistic proximity to the host country. We use these group dummies as control variables in our multivariate analyses.
} 
of a rejection of the traditional role model in Western societies since the 1950s. It is aimed at equity between women and men, and the dissolution of the traditional division of labor. In the egalitarian model, gender is not linked to specific social roles, but the division of labor is negotiated by the two spouses, who have equal rights.

Societies differ in the extent to which the ideal of gender equality is institutionalized. In German society, gender equality is still not completely implemented in practice but it is deeply rooted in the society's canon of values. In contrast, large sections of the immigrant population come from countries with more traditional gender role models. ${ }^{6}$ We expect that these macro conditions in the context of origin shape peoples' attitudes beyond the process of migration to Germany. Immigrants who come from a country with relatively low gender equality are likely to have internalized more traditional gender roles, and vice versa.

We assume that gender roles in the country of origin affect immigrants' name choices for their descendants in the host country: in societies with traditional gender roles, the continuation of family traditions and ethnic origin should be linked to masculinity more strongly than in societies with more egalitarian gender role models. By choosing names from the home country for sons, reflecting family and ethnic tradition, this connection to tradition can be expressed.

We suggest that the strategy of choosing assimilated names for daughters, in order to protect them from ethnic discrimination, as suggested by Sue and Telles (2007, p. 1411), is also grounded in gender roles and specific conceptions of femininity: traditionally, masculinity is associated with strength, dominance, and assertiveness, whereas femininity is linked to weakness and vulnerability. The more traditional the internalized gender roles, the stronger the protective mechanism should be, and the more likely parents are to give their daughters assimilated names.

We are not able to measure the underlying motives of the parents' name choice directly as they are not part of our dataset. We can only observe the outcome in terms of the first names that are chosen for girls and boys. Based on the literature, we have established theoretical arguments for the finding of gender inequality in naming and have tested the hypotheses that we can derive from theory empirically. We expect that the extent of gender differences in name giving varies depending on the context of origin: it should be strongly pronounced for immigrants from countries with traditional gender roles, where gender equality is only weakly institutionalized. In these groups, male descendants should particularly often receive first names that are common in the home country, and female descendants should be more likely to receive "protective," assimilated names (hypothesis 1a).

\subsubsection{Religious Affiliation}

Although connected to a country's gender role regime, religion has an independent effect on peoples' attitudes towards gender roles, as shown by Gerhards et al. (2009). Thus, we expect a respondent's religious affiliation to have an impact on name giving,

\footnotetext{
6 We will measure each country's level of institutionalized gender equality using the Gender Development Index. Germany is ranked \#4; Turkey, the country of origin of most immigrants in Germany, is ranked \#71.
} 
mediated by attitudes towards gender roles. We assume that it affects the likelihood of boundary crossing in general and impacts on gender differences in name giving in particular, independently of and in addition to the degree of the institutionalization of gender equity in the host country.

Several, mostly internationally comparative studies have shown that Muslims have more traditional gender role attitudes than people of any other religion (Fish 2002; Norris and Inglehart 2002; Moghadam 2003; Ross 2008; Alexander and Welzel 2011). ${ }^{7}$ This pattern also applies to immigrants in Germany: a representative study of Christian and Muslim immigrants in Germany has shown that the proportion of respondents supporting traditional, patriarchal gender role attitudes is higher among Muslims than among Christians (Becher and El-Menouar 2014, p. 5). ${ }^{8}$

The sources of these differences are controversially discussed in the literature. Some authors have tried to show that traditional gender roles are integral to and deeply rooted in Islam (Inglehart and Norris 2003; Alexander and Welzel 2011). Others state that the correlation with structural factors might explain the fact that Muslims have more traditional gender role attitudes than any other religious group. A third argument claims that distinct traditional gender roles are rooted in all religions; however, unlike Islam, the Christian religions have gone through a process of secularization that has also affected gender roles, promoting the rise of more egalitarian gender role attitudes (Inglehart and Norris 2003).

In this article, we cannot test the underlying explanatory mechanisms, but rather base our assumption on the empirical findings that Muslims seem to have more traditional gender role attitudes than any other religious groups on average. Thus, we hypothesize that the gender difference in boundary crossing in immigrants' name choices is more pronounced among Muslims than in any other religious group. Male descendants of Muslims receive names of the home country particularly often.

Furthermore, we expect differences between the various groups within Christianity. Previous studies have shown that members of Orthodox Christian groups have more traditional gender role attitudes than Protestant or Roman Catholic Christians (Inglehart and Norris 2003, p. 67). Consequently, we expect an internal differentiation within Christianity: we assume that in the group of Orthodox Christians we will find the most pronounced gender differences in naming of all Christian religious groups. Empirical evidence for differences in gender role attitudes between Roman Catholic and Protestant Christians is scarce and inconsistent; contrary to expectations, some studies found that Roman Catholics had more egalitarian gender role attitudes than Protestants (Gerhards et al. 2009, p. 525). Therefore, we do not

\footnotetext{
${ }^{7}$ However, it is important to note at this point that immigrants and their descendants from Muslim countries who migrated to Western countries adapt to the host country's gender role regime over time. Alternatively, their gender role attitudes are different from those in the population in their countries of origin (Inglehart and Norris 2003; Alexander and Welzel 2011).

${ }^{8}$ Some authors state that there is an effect of the strength of religiosity (measured by church attendance) on gender role attitudes, independently of the type of religious affiliation. However, when controlling for religious affiliation, we do not find any effects of religiosity (church attendance) on boundary crossing in name giving in general and with regard to the gender difference in particular. This is in line with findings of previous studies indicating that the type of religion matters more than the strength of religiosity (Inglehart and Norris 2003, p. 67; Alexander and Welzel 2011).
} 
have a directional hypothesis about any differences between Roman Catholics and Protestants, but we differentiate between the two groups in the empirical analyses.

Furthermore, our data contain the categories "other religious denomination" as well as "no denomination." For the first group, we are not able to formulate any hypotheses, as we do not have any detailed information about which kind of other affiliation respondents belong to. For the group of respondents who are unaffiliated with any religion, we expect less pronounced gender differences in naming, as a secular orientation often goes hand in hand with egalitarian gender role attitudes.

In summary, we assume that gender role attitudes are shaped by religion. Therefore, a respondent's religious affiliation should have an impact on the extent of gender difference in name choice. We follow the same argument as in the previous section and assume that the gender gap is the smallest in the group of those without any religious affiliation, followed by Roman Catholic and Protestant Christians, and then by Orthodox Christians, and should be most pronounced for Muslims (hypothesis 1b).

At the same time, religious affiliation is linked to the overlap of the first name pools between origin and destination country, as many first names have a religious origin. We expect that this affects the overall probability of boundary crossing, but not necessarily the gender gap in particular. ${ }^{9}$

\subsection{Integration into the Host Society}

Immigrants bring a specific set of resources and capital to the host country, such as educational certificates acquired in the home country. Integration in the host society is usually easier, the better the capital meets demand and approval in the host country (Chiswick 1991; Friedberg 2000; Esser 2001; Becker 2011). The classic straight-line theory of assimilation posits that with increasing integration immigrants become more and more exposed to the host society and ultimately leave their traditional cultural markers behind and adopt those of the host society. Milton M. Gordon hypothesized that "once structural assimilation has occurred, all of the other types of assimilation will naturally follow" (Gordon 1964, p. 80-81). Following this argument, immigrants should be more likely to opt for the strategy of boundary crossing in naming, irrespective of their child's gender, with increasing structural integration.

The assumptions of classic assimilation theory have been criticized by many authors with a variety of arguments (for an overview, see Alba and Nee 2005). Some studies have shown that ethnic identity may be maintained or even reemerge with increasing integration into the host society. Thus, an increased level of structural integration is not necessarily associated with a greater likelihood of boundary crossing in naming. Another aspect concerns recent literature on the so-called "integration

\footnotetext{
9 However, the latter assumption is empirically hard to prove and must be considered a potential limitation of our analysis. As we do not have any information on the proportion of religious names in each group, we will strictly speaking not be able to test the claim that the proportion of male and female names with a religious background and an overlap with the German name pool does not differ systematically between religious groups.
} 
paradox" (Steinmann 2018). By this, one understands that well-integrated immigrants tend to perceive not less but more discrimination in the host country. Building on this finding, one could expect two opposite effects on immigrants' name choice linked to structural integration. On the one hand, experiences of rejection might foster re-ethnicization (Skrobanek 2009), manifested in the strategy of boundary maintenance in naming. On the other hand, by perceiving more discrimination with increased integration, parents might be more likely to opt for boundary crossing in order to prevent their offspring's discrimination in the host society. Indeed, previous studies have shown that immigrants are more likely to choose names from the host country, the better they are integrated into its society (Lieberson 2000; Gerhards and Hans 2009).

However, our predominant interest in this article is not boundary crossing in naming in general, but with regard to gender differences in particular. In this respect, we expect that the level of integration into the host country affects the gender difference in naming because of an adaption of the host society's core values: the better immigrants are integrated into the host society, the more strongly they will have internalized its values. As the idea of gender equality is rooted in the value canon of German society, we assume that with increasing levels of integration, the idea of gender equality will be internalized, with the result that gender role attitudes of well-integrated immigrants will be more egalitarian than those of their less wellintegrated counterparts. ${ }^{10}$ As discussed in the previous section, supporting the idea of gender equality should narrow the gender gap in naming practices.

We differentiate the following dimensions of integration: structural and social integration, ${ }^{11}$ and emotional identification with the host country. We assume that the positive association between integration and gender equality in naming applies similarly to different dimensions of integration. The different dimensions of integration are not independent of each other but mutually dependent. Their interdependencies are not the focus of our analyses, but including them in the multivariate model simultaneously enables us to determine the independent effect of each of the single dimensions of integration.

\subsubsection{Structural Integration}

Throughout this paper, structural integration is defined by German citizenship and immigrants' educational level. The attainment of citizenship is conditional on successful integration in other dimensions, for instance, regarding language skills and employment in the host country. Citizenship is thus an indicator of a certain level of structural integration in the host country and, moreover, is also associated with

\footnotetext{
10 Obviously, this is only true when the level of gender equality is indeed higher in the host country than in the country of origin.

11 In integration research, language acquisition of the host country is considered a key determinant of integration (Chiswick 1991; Esser 2001). However, including German language skills in our analyses would dramatically reduce our sample size, as the item is part of specific subsamples only. We have analyzed the effect of German language skills in a restricted sample and found no effects on boundary crossing in general and on the gender gap in particular (also see Becker 2009). Therefore, we do not include language skills in the analyses presented in this paper.
} 
emotional identification. On the other hand, it is assumed that immigrants only aspire to citizenship if they identify themselves with their host country, while on the other hand, after having acquired citizenship, people increasingly identify with their host countries, as shown in previous studies (Howard 2003; Fick 2016).

We assume that both citizenship and educational level promote the likelihood of boundary crossing in general. In addition, we hypothesize that with increasing structural integration, immigrants identify more strongly with the host society's values, such as gender equality. Therefore, the gender gap in naming should become smaller as the level of structural integration in regard to citizenship and education increases (hypothesis 2a).

\subsubsection{Social Integration}

Social integration refers to the social ties of immigrants to members of the majority society. Previous studies have considered friendships as well as partnerships/ marriages as important dimensions of social integration (Haug and Pointner 2007; Sue and Telles 2007). Regarding name giving, the latter should be particularly important, as spouses are directly involved in the choice of names for their children.

We assume that in partnerships with one German spouse (we will refer to this constellation as intermarriage, independently of the legal status of the partnership), the probability of boundary crossing is higher than when both partners are immigrants (Sue and Telles 2007). In respect of gender differences in naming we assume that immigrants whose spouse belongs to the majority society have a 'host countryspecific social capital' that promotes their own internalization of the host society's norms and values, such as gender equality. We thus expect gender differences to be smaller if one of the spouses is a member of the majority society. We also analyze whether there is a difference depending on which of the spouses is a member of the majority society (also see: Sue and Telles 2007): provided that (1) gender roles are more traditional in the home country than in the host country and (2) in the case of traditional, patriarchal gender role attitudes, the male spouse is more dominant in the process of choosing a name, the origin of the fathers should be particularly important. Therefore, we expect the probability of boundary crossing to be highest when the father is a member of the majority society. At the same time, the gender difference in naming should be smallest in this constellation, followed by intermarriage with the mother as a member of the majority society, and then by partnerships where both spouses have a migration background (hypothesis $2 \mathrm{~b}$ ).

\subsubsection{Emotional Identification with the Host Country}

Emotional identification is an inner process that is influenced by external conditions but is not as strongly dependent on the surrounding conditions in the host country as other dimensions of integration, such as educational level and citizenship. Feelings of belonging play an important role in emotional identification: "Belonging is a dynamic emotional attachment that relates individuals to the material and social worlds that they inhabit and experience" (Wood and Waite 2011, p. 201). 
Assuming that the process of name giving is accompanied by an emotional dimension of integration, emotional identification with the host country should increase the likelihood of boundary crossing in general. Again, we are particularly interested in gender differences. We expect that strong emotional identification with the host country promotes the internalization of its core values, such as the ideal of gender equality; therefore, gender differences in naming should decrease with increasing emotional identification with the host country (hypothesis 2c).

\section{Data and Methods}

\subsection{Dataset and Sample}

We use data from the German Socio-Economic Panel Study (GSOEP), a household survey that has been conducted in Germany since 1984 (Goebel et al. 2019). The GSOEP includes immigrants of both the first generation (who were born abroad) and the second and third generations (who were born in Germany, but whose parents or grandparents were born abroad). Our sample is restricted to immigrants of the first generation who gave birth to at least one child in Germany. The sample also includes first-generation migrants who are married to or live in a partnership with a German citizen. We only use information on names of children born in the country of destination. We include families with more than one child in the sample; we correct for the autocorrelation of the units by clustering the standard errors on a household level. The families in our sample come from 49 different countries. After the exclusion of cases with missing values, our sample consists of $N=905$ children and their families. Although our dependent variable (child's first name) and our key independent variable (child's gender) refers to the child, our level of analyses are the families, as we are interested in the parents' decision.

\subsection{Onomastic Coding of First Names}

In the GSOEP, the first names of all individuals in a household are collected, but because of data security they are not part of the scientific use file. For our project we were provided with an anonymous list of all first names ever collected in the GSOEP. Names were assigned to one or several countries or regions based on their prevalence in different countries and their historical origin by a professional onomatologist (Humpert and Schneiderheinze 2000). This coding provides us with information on whether a first name is German, Turkish, Russian, and so on. Names that could not be assigned or that were obviously false (i.e. nicknames), were excluded from the analyses $(2.9 \%)$. Originally, the onomastic procedure was invented for the identification of immigrants in administrative data, e.g., for sampling reasons. Usually, first name and surname are required in order to assign names to certain countries; a procedure based on first names only is imprecise. Therefore, we checked all names a second time to determine whether or not they are common names in Germany. This includes names of foreign origin that have been adopted by the German majority society. As a result, we have more reliable coding regard- 
ing the information on whether a first name is common in Germany or not. As we were only able to conduct the supplementary coding regarding the question, whether a name is common in Germany or not, we were unfortunately unable to generate a third category of "hybrid names" that are common in both the home and host countries. For this purpose, it would have been necessary to do the ex-post coding for all languages that are represented in our sample, which was beyond the scope of this project. Therefore, we can only differentiate between names that are common in Germany and names that are not.

The coding information was then merged with the current personal ID in the GSOEP, and the actual first names were deleted in order to guarantee respondents' anonymity. This provides us with a dataset that includes information on the first names of all individuals in the GSOEP stating whether or not their first name is common in Germany.

\subsection{Dependent and Independent Variables}

The dependent variable of our analysis is boundary crossing or boundary maintenance in name choice. We differentiate between names that are common in Germany (boundary crossing) and names that are not common in Germany (boundary maintenance). The key independent variable is the child's gender (male [1], female [0]).

We investigate the degree of institutionalized gender equality as one important feature of the context of origin. We measure the institutionalized gender equality by means of the UN Gender Development Index ${ }^{12}$ (hereafter GDI). The GDI measures inequality between men and women in three dimensions, which are also included in the Human Development Index: (1) life expectancy, (2) education, and (3) living conditions (Gross National Product). For each of the dimensions, the quotient of the average within the male and female population was computed and combined into a composite measure. The closer this score is to " 1 ", ${ }^{13}$ the more equal men and women are, and the more gender equality can be considered to be institutionalized. For our analyses we have categorized the respondents' countries of origin into three groups: (1) countries with a GDI of more than 0.5 standard deviation (SD) below the average have low gender equality, (2) countries with a GDI varying up to 0.5 SD around the mean have moderate gender equality, and (3) countries with a GDI that is more than $0.5 \mathrm{SD}$ above the mean have strong gender equality. As the scores are quite stable over time (Pearson's r between 1995 and 2005=0.97), we use the GDI score of the year 2000 for all respondents. By collapsing the score into three categories, subtle changes over time are negligible. ${ }^{14}$ Measuring institutionalized gender equality by means of the GDI does not allow us to determine the dominant

\footnotetext{
12 We have conducted robustness checks with alternative measures of the institutionalized level of gender equality (Gender Inequality Index of the UN, female share in parliament, Social Institutions, and Gender Index); the main results do not change.

13 Values higher than "1" are theoretically possible if gender differences are to the advantage of women.

14 We have run all models with an alternative, interval scale coding of the GDI (z-transformed) as a robustness check. Results remain unchanged. We have provided the result of such a robustness check of the final model (equivalent to Fig. 1 in the main text and Fig. 2 in the appendix).
} 
gender roles in a country directly. However, a robustness analysis of a restricted sample has confirmed that gender role attitudes are highly correlated with the degree of institutionalized gender equality in the home country. ${ }^{15}$

Furthermore, we analyze the religious affiliation of our respondents. We differentiate between (1) Roman Catholic, (2) Protestant, (3) Orthodox Christian, (4) Muslim, and (5) other religious affiliation or (6) no religious affiliation. ${ }^{16}$

To measure integration into the host society, we consider structural and social integration as well as emotional identification with the host country. Where possible, we use the most recent information at the time of the child's birth in case of timevarying variables. If information were not available in the last wave, we would use the second, third, etc. to last. We use information from a maximum of seven years before the child's birth. For the cases where parents were assigned to different categories, we used the score of the father. In case of intermarriage, the score of the migrant spouse was used. In the case of missing values for one parent, we used the information on the other spouse.

Structural integration is operationalized by German citizenship (at least one spouse has German citizenship) and the educational level indicated by the "International Standard Classification for Education 2011" (ISCED 0/2=low; ISCED $3 / 5=$ medium; ISCED $6 / 8=$ high educational level). Social integration is operationalized by intermarriage. We consider whether and which of the two spouses is native German: (1) none of the two, (2) the mother, or (3) the father. In order to assess the degree of emotional identification, we use information on "how German" respondents feel ([1] not at all/hardly [2] to some extent [3] predominantly/completely).

\subsection{Control Variable}

In order to control for other aspects of cultural proximity between immigrants' country of origin and Germany, and primarily for linguistic proximity, which is reflected in different degrees of overlap with the German first name pool, we control for the origin group in the multivariate analyses. We differentiate between migrants from (1) Turkey, (2) Former Yugoslavia, (3) Commonwealth of Independent States (former Soviet Republics), (4) Eastern Europe, (5) Romanic countries, (6) Greece, (7) Africa, (8) Middle East, and (9) Western Europe. Furthermore, we control for the parents' duration of stay in Germany. In the case of different years of immigration, we refer to the spouse with a longer stay. Cases with missing values on one or more of the variables were excluded from the analyses. In total, we had information on the first names of 6640 individuals who were born in Germany with at least one parent born in one of the countries that belong to the origin groups included in

\footnotetext{
15 We have run a separate correlation analysis on the country level between the Gender Inequality Index (year 2000) and the public's gender role attitudes based on respondents' agreement to gender equality in the job, politics, and education derived from the World Value Survey (wave 1999-2004) on a subset of countries. The analysis revealed that institutionalized gender equality and gender role attitudes are highly correlated (Pearson's $r=0.59, p=0.000$ ).

16 If the parents were born in countries other than Germany and were assigned to different GDI categories or religious groups, we used the information of fathers. In the case of intermarriage, we used the information on the spouse with the migration background.
} 
our analyses. This is the group of children that could potentially be included in our analyses. However, in only 1156 cases did at least one parent take part in the GSOEP and was interviewed within a time period of 7 years before the birth of the child. The GDI score could be assigned to 1046 cases. The sample was further reduced owing to item non response on one or several independent variables and the final sample consisted of 905 cases.

\subsection{Analytic Strategy}

First, we investigate the associations between the independent variables and boundary crossing in name giving in bivariate analyses, separately for girls and boys. By doing so, we are able to observe descriptive gender differences in naming at different levels of our explanatory variables. Second, we use logistic regression in order to estimate a multivariate model. In the initial model, we first estimate the main effects of our explanatory variables on parents' likelihood to choose a name that is common in Germany, whereas the child's gender and all other covariates are controlled. In a third step, we analyze the effects of moderation of the independent variables on the gender effect by including interaction effects between the child's gender and each independent variable separately in the initial multivariate model. By doing so, we are able to determine whether and to what extent the gender gap in boundary crossing varies by the context of origin, while holding the degree of integration in the host society constant, and vice versa.

\section{Empirical Findings}

\subsection{Bivariate Analyses}

Table 1 shows the proportion of children who have received a name that is common in Germany in total, as well as separately for girls and boys at different levels of the independent variables. The last two columns of the table present indicators for the gender gap in naming: First, the absolute difference in the proportion of boundary crossing between girls' and boys' names and second, a ratio calculated by means of the quotient of the proportion of boundary crossing in girls' and boys' names. The higher the ratio, the greater the gender gap with regard to the relative difference in boundary crossing between female and male descendants.

The first row presents the overall proportion of boundary crossing. In the total sample, the proportion of children who have received a name that is common in Germany is $49.17 \%$. The share is substantially higher among female than among male descendants. The absolute difference between girls' and boys' names is 14.49 percentage points. The gender ratio in name giving amounts to 1.35 . This means that on average, parents are $35 \%$ more likely to choose the strategy of boundary crossing when the child is a girl. This indicates that previous findings on gender differences in immigrants' naming practices are confirmed in our sample, which covers more origin groups than previous studies. 
Table 1 Proportion of boundary crossing (BC) in name-giving for female and male descendants at different levels of the independent variables $(N=905)$, in \%. (Data source: GSOEP v32, own computations)

\begin{tabular}{|c|c|c|c|c|c|}
\hline & $\begin{array}{l}\text { Total } \\
\% \mathrm{BC}\end{array}$ & $\begin{array}{l}\text { Females } \\
\% \mathrm{BC}\end{array}$ & $\begin{array}{l}\text { Males } \\
\% \text { BC }\end{array}$ & $\begin{array}{l}\text { Difference } \\
(\% \mathrm{f}-\% \mathrm{~m})\end{array}$ & $\begin{array}{l}\text { Ratio } \\
(\% \mathrm{f} / \% \mathrm{~m})\end{array}$ \\
\hline Total sample & 49.17 & 56.36 & 41.87 & 14.49 & 1.35 \\
\hline \multicolumn{6}{|l|}{ Gender equality } \\
\hline Low GDI & 9.35 & 16.57 & 3.01 & 13.56 & 5.51 \\
\hline Medium GDI & 63.54 & 71.55 & 54.26 & 17.30 & 1.32 \\
\hline High GDI & 85.67 & 87.21 & 83.97 & 3.23 & 1.03 \\
\hline \multicolumn{6}{|l|}{ Religious affiliation } \\
\hline Catholic & 77.58 & 80.00 & 74.80 & 5.20 & 1.07 \\
\hline Protestant & 85.13 & 88.46 & 81.43 & 7.03 & 1.09 \\
\hline Orthodox Christian & 62.65 & 80.48 & 45.24 & 35.24 & 1.78 \\
\hline Muslim & 9.32 & 14.96 & 2.75 & 12.21 & 5.44 \\
\hline Other & 6.83 & 13.16 & 3.79 & 9.37 & 3.47 \\
\hline None & 47.5 & 50.00 & 44.44 & 5.56 & 1.13 \\
\hline \multicolumn{6}{|l|}{ Citizenship } \\
\hline Foreign citizenship & 24.90 & 34.51 & 15.73 & 18.78 & 2.19 \\
\hline German citizenship & 82.25 & 84.08 & 80.22 & 3.86 & 1.05 \\
\hline \multicolumn{6}{|l|}{ Educational level } \\
\hline Low education & 31.76 & 43.18 & 19.51 & 23.67 & 2.21 \\
\hline Medium education & 46.87 & 53.69 & 40.06 & 13.63 & 1.34 \\
\hline High education & 66.91 & 75.62 & 59.42 & 16.15 & 1.62 \\
\hline \multicolumn{6}{|l|}{ Intermarriage } \\
\hline No intermarriage & 48.09 & 56.11 & 40.41 & 15.70 & 1.39 \\
\hline German mother & 42.22 & 47.82 & 36.36 & 11.46 & 1.46 \\
\hline German father & 63.24 & 66.18 & 59.18 & 7.00 & 1.12 \\
\hline \multicolumn{6}{|l|}{ Identification Germ } \\
\hline Weak & 29.95 & 39.37 & 20.00 & 19.37 & 1.97 \\
\hline Medium & 37.31 & 47.20 & 28.67 & 18.53 & 1.65 \\
\hline Strong & 69.49 & 72.55 & 66.13 & 6.42 & 1.09 \\
\hline
\end{tabular}

Next, we are interested in differences in boundary crossing between immigrants from different contexts of origin with regard to gender roles. First, we look at the institutionalization of gender equality in the home country, which we suggest is expressed by the GDI. In total, the higher the GDI in the country of origin, the more likely parents are to choose a name that is common in the host country. This relationship applies to both female and male first names. At the same time, the gender gap decreases with increasing GDI: although daughters receive a name common in the host country more than five times as often as sons among the immigrants from countries with low GDI and pronounced gender inequality, the relative difference between girls and boys expressed in the gender ratio decreases with increasing GDI. There is not a greater difference between girls' and boys' names among immigrants from countries with a high degree of institutionalized gender equality. Hence, the 
hypothesis that the gender difference in naming is smaller the more egalitarian the gender role regime is in the country of origin is supported.

The second feature related to the context of origin is religious affiliation. The bivariate associations show that name giving in general, as well as with regard to gender in particular, is strongly affected by religion. In total, Protestant Christians choose boundary crossing most often, followed by Roman Catholics, Orthodox Christians, and respondents without any religious affiliation. In contrast, immigrants in the group of other religious affiliations choose boundary maintenance most often. As described earlier, we cannot interpret this finding as we do not know which religions this category contains. Muslims very often opt for boundary maintenance too: less than $10 \%$ of Muslim descendants in our sample have received first names that are common in the host society. At the same time, the gender differences in naming are most pronounced in the group of Muslims: daughters are more than five times more likely than sons to receive a first name that is common in the host country. In contrast, the relative gender gap in naming is significantly less pronounced in the groups of Roman Catholics and Protestants; here, the gender ratio is close to 1, indicating that there is hardly any gender gap in naming in these groups. The same is true for respondents without any religious affiliation who have a very low gender ratio of 1.13 .

Next, we turn to gender differences with regard to different dimensions of integration into the host country. The total frequency of boundary crossing increases and the gender difference in boundary crossing decreases the better the parents are structurally integrated in the host society. This holds both for citizenship and educational level. In total, parents with a German citizenship are more likely to opt for boundary crossing than parents with a foreign citizenship. At the same time, the relative "advantage" for daughters is only existent for children of parents with a foreign citizenship. In this group, the likelihood of girls receiving a name that is common in Germany is twice as high as that of boys. In contrast, there is hardly any gender gap in naming for children whose parents have a German citizenship: the gender ratio is close to 1 . A similar pattern can be observed with regard to the parents' educational level. With increasing integration, the share of children with a name that is common in the destination country increases, while at the same time, the gender gap decreases, both in absolute and relative terms. Especially for boys' names, the increase in boundary crossing along the parents' educational levels is strongly pronounced.

Next, we observe proportions in boundary crossing depending on immigrants' social integration. In families with a German father, the proportion of children who received a name that is common in Germany is highest. Contrary to our expectations, among the families with German mothers, the respective share is lower than in families with both parents born abroad. The gender gap does not vary strongly by parents' social integration; the relative "advantage" for female descendants ranges between 12 and 39\%. The pattern is in accordance with the theoretical assumption that the gender gap is smaller when one of the parents was born in Germany; when the father in particular was born in Germany, the gender gap is only weakly pronounced (1.12). 
Last, we analyze the association between emotional identification with Germany and gender differences in naming. As expected, the relationship between boundary crossing and emotional identification is generally positive: the stronger the parents' identification with the host country, the larger the proportion of children who received a name that is common in the host country. At the same time, the gender gap in naming substantially decreases with increasing emotional identification with the host country.

Taken together, most of the theoretical assumptions regarding immigrants' level of integration in the host country are supported in the bivariate analyses. The better immigrants are integrated structurally, socially, and emotionally, the more likely they are to opt for the strategy of boundary crossing and the less their strategy of boundary work in naming is affected by their child's gender.

\subsection{Multivariate Analyses}

In the multivariate analyses, we investigate whether the associations between the explanatory variables and boundary crossing remain substantial while all other model variables are controlled. All children are included in this model, and gender is an independent variable. Again, the main question is whether the child's gender yields different effects on the likelihood of boundary crossing. Therefore, we will include interaction terms between the independent variables and the child's gender one after another in the initial model in order to establish gender-specific differences in the effects of the independent variables. Based on these models and gender-specific predicted probabilities derived from them, we compute the gender ratio in boundary crossing at different levels of our explanatory variables.

The main effects of the explanatory variables are shown in the initial model in Table 2. The model includes ethnic group as a control variable in order to account for language similarities and overlaps in the name pools between the host country and the country of origin (not shown). As we did not find any significant differences between Catholic and Protestant Christians, we combined these two categories.

The gender gap remains strong and significant under control of all other independent variables: male descendants receive names that are common in the host country less often than female descendants. With regard to the degree of gender equality in the home country, the difference between strong and weak equality remains substantial and (weakly) significant in the multivariate model, whereas the difference between medium GDI and the reference category narrowly fails statistical significance at the $90 \%$ level; however, the positive coefficient points in the expected direction of the effect. Religious affiliation remains a significant explanatory variable for name choice, with the exception of Orthodox Christians. This group does not significantly differ from the reference category (Protestant/Catholic Christians). In the multivariate analyses, the group of Muslims turns out to be least likely to choose boundary crossing, followed by migrants with other religious affiliations. Those with no affiliation lie in between these groups and the reference category of Catholics/Protestants. Taken together, features of the context of origin prove to be substantial predictors of immigrants' strategy of boundary crossing in naming. 
Table 2 Logistic regression on the likelihood of boundary crossing in female and male descendants' names $(N=905)$. (Data source: GSOEP v32, own computations)

\begin{tabular}{|c|c|c|}
\hline & $\begin{array}{l}\text { Coefficient } \\
\text { (S. E.) }\end{array}$ & $p$-value \\
\hline Sex: male & $\begin{array}{l}-1.025 \\
(0.215)\end{array}$ & 0.000 \\
\hline \multicolumn{3}{|l|}{ GDI (ref.: low) } \\
\hline GDI medium & $\begin{array}{l}0.905 \\
(0.596)\end{array}$ & 0.129 \\
\hline GDI high & $\begin{array}{l}1.059 \\
(0.602)\end{array}$ & 0.078 \\
\hline \multicolumn{3}{|c|}{ Religious affiliation (ref.: Christian) } \\
\hline Orthodox Christian & $\begin{array}{l}0.202 \\
(0.391)\end{array}$ & 0.605 \\
\hline Muslim & $\begin{array}{l}-1.680 \\
(0.397)\end{array}$ & 0.000 \\
\hline Other & $\begin{array}{l}-1.522 \\
(0.523)\end{array}$ & 0.004 \\
\hline None & $\begin{array}{l}-1.138 \\
(0.435)\end{array}$ & 0.009 \\
\hline German citizenship & $\begin{array}{l}1.027 \\
(0.301)\end{array}$ & 0.001 \\
\hline \multicolumn{3}{|l|}{ Education (ref.: low) } \\
\hline Education: medium & $\begin{array}{l}0.541 \\
(0.315)\end{array}$ & 0.086 \\
\hline Education: high & $\begin{array}{l}0.662 \\
(0.360)\end{array}$ & 0.066 \\
\hline \multicolumn{3}{|c|}{ Intermarriage (ref.: none) } \\
\hline German mother & $\begin{array}{c}-0.434 \\
(0.326)\end{array}$ & 0.183 \\
\hline German father & $\begin{array}{l}-0.332 \\
(0.351)\end{array}$ & 0.344 \\
\hline \multicolumn{3}{|c|}{ Identification with Germany (ref.: low) } \\
\hline Medium identification & $\begin{array}{l}0.278 \\
(0.275)\end{array}$ & 0.321 \\
\hline High identification & $\begin{array}{l}0.371 \\
(0.281)\end{array}$ & 0.188 \\
\hline Constant & $\begin{array}{l}-21.509 \\
(23.277)\end{array}$ & 0.355 \\
\hline Observations & 905 & - \\
\hline Pseudo $R^{2}$ & 0.4982 & - \\
\hline
\end{tabular}

Control variables: ethnic group; duration of stay in Germany

Turning to the level of integration, structural integration also remains a predictor of name choice in the multivariate analysis: immigrants with German citizenship are more likely to choose boundary crossing than immigrants with foreign citizenships. Medium and high educational levels yield weakly significant but positive effects on boundary crossing. Under control of the context of origin with regard to gender roles and religion, as well as linguistic aspects, immigrants are more likely to opt for boundary crossing in naming, the better they are integrated structurally. 
Surprisingly, social integration operationalized by intermarriage shows a negative association with the likelihood of boundary crossing net of all other explanatory variables: immigrants tend to be less likely to opt for boundary crossing when they have a German spouse. There is not a big difference with regard to whether the German parent is the mother or the father of the child. Both constellations tend to decrease the likelihood that the child receives a name that is common in Germany when features of the context of origin and structural and emotional integration into the host country are controlled.

The coefficients for emotional identification with the host country fail to reach statistical significance. The emotional component of integration seems to be absorbed by the "hard" dimensions of structural integration. However, the effects of emotional identification point in the expected direction.

Although not all explanatory variables show significant main effects on boundary crossing, they might still be relevant moderators of the gender effect as they may exhibit differential effects for female and male descendants. We analyze our main question in the following section: is the gender effect on boundary crossing moderated by features of the context of origin and by the level of integration into the host country?

\subsection{Gender Differences in the Probability of Boundary Crossing}

We include interaction effects between the child's gender and the explanatory variables in the initial model of Table 2. Based on these estimates, we compute predicted probabilities for boundary crossing depending on the level of the respective explanatory variable separately for girls and boys. We use these scores to calculate a quotient that is comparable with the gender ratio in Table 1, but now the gender ratio is based on the multivariate model and therefore expresses the gender gap at different levels of the independent variables while all other variables are held constant at their means. The gender ratio expresses the factor by which the predicted probability of boundary crossing of girls exceeds that of boys depending on origin-specific factors and the level of integration into the host country. The greater the gender ratio, the larger the gender difference in the predicted probability for boundary crossing in favor of girls. On the contrary, a value below 1 (left of the dashed line) would indicate that boys have a higher predicted probability of receiving a name that is common in Germany. However, this is not the case in any of the predicted scenarios. We integrate the interaction terms one by one; technically, we estimate six different models. The results of this analysis are presented in Fig. 1.

The model confirms a significant moderation of the gender effect by the context of origin, which holds under control of the other independent variables: the higher the GDI in the home country, the lower the gender gap. Among immigrants from countries with strong institutionalization of gender equality, there is hardly any difference in the strategies of boundary work between girls' and boys' names. These findings strongly support hypothesis 1a. Likewise, the gender ratio differs strongly from religious affiliation. It is the least pronounced among immigrants with Roman Catholic, Protestant, and without any religious affiliation, and most pronounced among Muslims. In the latter group, the predicted probabilities of boundary crossing 


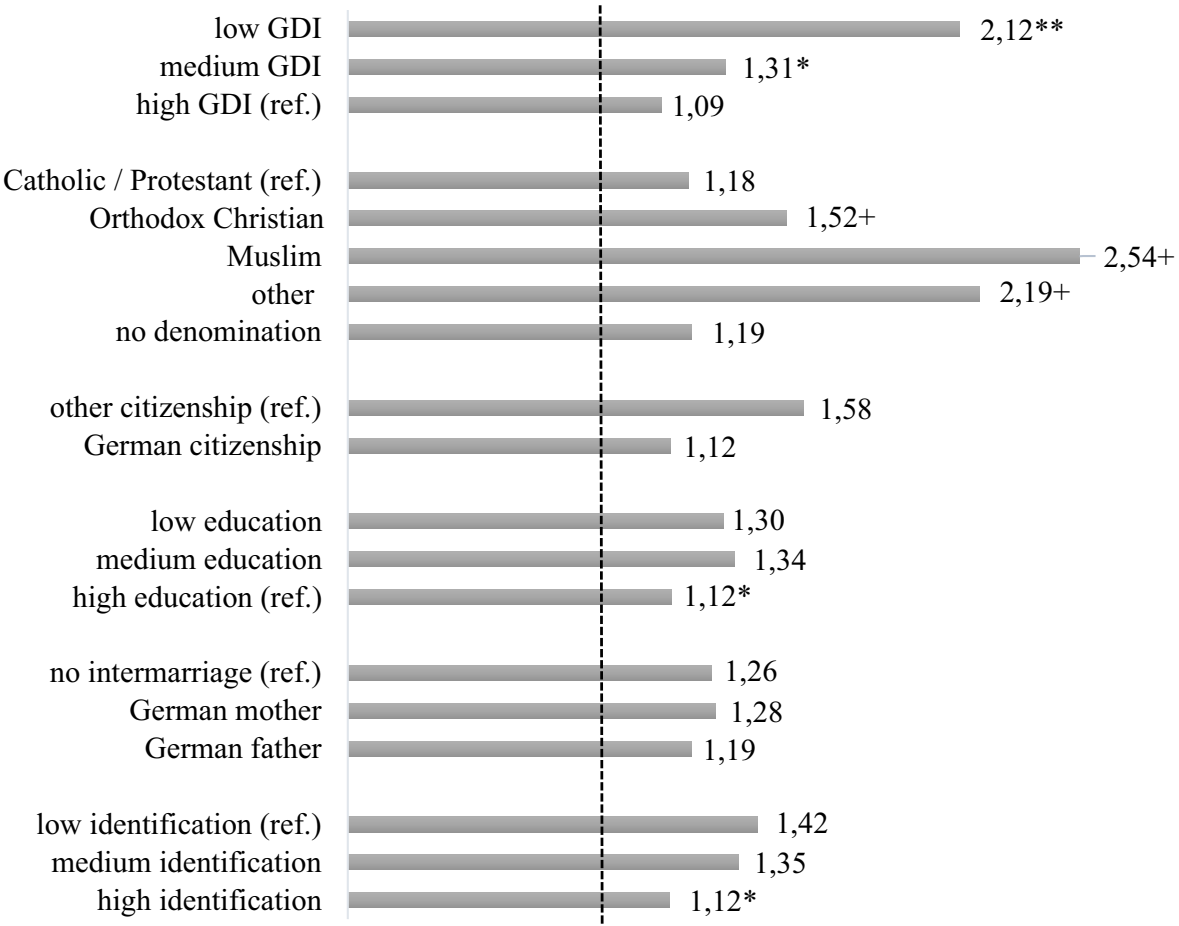

Fig. 1 Gender ratios in the predicted probabilities of boundary crossing at different levels of the explanatory variables derived from logistic regression analyses $(N=907)$. Data source: GSOEP v32, own computations; significance levels: $+p<0.1,{ }^{*} p<0.05, * * p<0.01$

of girls' names exceed that of boys by the factor 2.5. Hence, hypothesis $1 \mathrm{~b}$ is supported by the multivariate analyses.

Taken together, the findings from the multivariate analyses strongly support our hypotheses that internalized gender roles affect gender differences in naming. Even though we cannot explicitly test the specific motives of name giving, we have suggested that two main motives are decisive. First, traditional gender roles reserve the intergenerational transmission of family heritage to male descendants. Second, from the same perspective, female descendants are considered in greater need of protection. Therefore, parents with traditional gender role attitudes have an incentive to protect their daughters by giving them assimilated names. We suggested that both mechanisms are weaker the more egalitarian the parents' gender role attitudes are. Table 3 in the appendix provides more detailed information on this aspect: the predicted probabilities vary more strongly by GDI for boys than for girls. This indicates that in the traditional role model, the role of males has more explanatory power than the role of females (in need of protection) when it comes to name giving: we infer from this finding that it is the connection of masculinity and the transmission of family tradition that is the main driving mechanism behind the gender difference in naming. 
Furthermore, we test the hypothesis that the relevance of the child's gender for boundary crossing decreases with increasing levels of parental integration into the host society, because integration is suggested to go along with the internalization of core values of the host society, such as gender equality. With regard to structural integration, the expected pattern can be observed: although the gender ratio is strongly pronounced (1.6) in the group of immigrants with foreign citizenship, the difference between boys' and girls' names is far smaller when at least one of the parents has German citizenship (1.1). This finding supports hypothesis 2a. In terms of parents' educational level, we do not observe the expected clear educational gradient (hypothesis 2b): in accordance with our theoretical expectations, we find that the gender ratio is least pronounced among immigrants with a high educational level. However, the ratio is highest among immigrants with a medium level of education and the interaction is not statistically significant. The gender ratio does not vary substantially with immigrants' social integration into the host country. Families with a German spouse do not significantly differ from families with both parents born abroad. Hence, the gender ratio is not affected by intermarriage. Finally, emotional identification with Germany has a moderating effect on the gender effect in boundary crossing: the differences for boys and girls are most pronounced when parents' identification with the host country is weak (hypothesis $2 \mathrm{c}$ ).

\subsection{Robustness Tests}

There exists an alternative explanation for the gender difference in naming. The overlap between names that are common in the country of origin and the country of destination might be different for male and female names and might vary between the different groups of immigrants. In order to validate our findings with regard to these systematic differences in the gender gap in the overlap of the first name pools with the German name pool between the different origin groups, we conducted a robustness test for all models by creating an alternative control variable of the origin groups: the variable reflects the gender gap in the proportion of first names that are common in Germany in the first generation of migrants from the respective origin groups. As we expect no orientation towards the (later) destination country Germany, when the group of first-generation migrants was given first names by their parents, a potential gender gap that already occurs in the first generation is an indicator of the difference between boys' and girls' names in the overlap with the German first name pool. By controlling for this initial gender gap, the effects of the remaining variables are net of this "natural" difference in the degree of the overlap of the first name pools between girls' and boys' names. However, at the same time, the problem arises that the groups of origin can no longer be controlled simultaneously owing to the multicollinearity of this new measure. Therefore, one has to decide which of the two indicators is used as a control variable for linguistic proximity. Results indicate that the main findings remain unaffected and are even more pronounced when the alternative control variable is used (see appendix, Table 4). This is probably because the origin groups reflect cultural distance/proximity better than the gender gap of first names that are common in Germany within the first generation of migrants. 


\section{Conclusion}

Our analyses show that immigrants' name-giving practices are gendered: girls more often receive names that are common in the host society than boys. We find that this gender difference can be explained by both features of the country of origin and the level of integration into the host society. The design and the results of our study go beyond the scope of previous work in several dimensions. First, contrary to previous studies, we are able to include immigrants from various countries, enabling us to analyze the effect of the context of origin on name-giving practices. Thereby, we are able to differentiate between factors related to the country of origin and factors related to the level of integration in the host country. We show that both sets of factors contribute to explaining gender differences in naming, but that features of the context of origin yield the more pronounced effects on gendered patterns in naming than immigrants' level of integration.

Second, our data include more detailed information on structural, social, and emotional integration than previous studies. As shown, these are in large part important predictors, not only of boundary crossing in general but of the gender gap in boundary crossing in particular. Among the different dimensions of integration, structural integration yields the strongest effects on boundary crossing. On the one hand, this result might be considered to be in line with the assumptions of classical straight-line assimilation theory: the better immigrants are integrated, the more likely they are to adapt to the cultural signs of the host country. Following this argument, boundary crossing in naming may be interpreted as a sign of assimilation into the majority society in the host country. On the other hand, the results may be interpreted differently when considered from the perspective of the integration paradox. Better integrated immigrants may opt for boundary crossing because they are more aware of the problem of discrimination in the host country; by choosing assimilated names, they try to prevent their children from discrimination that they experience themselves. For this reason, it might not be straightforward to interpret boundary crossing in naming as an act of immigrants' greater identification with the host country, as suggested by previous work (Becker 2009). Whatever the motives are, children with names that are common in the host country will be likely to have an integration advantage over children with foreign first names. We will come back to this aspect after having discussed some limitations of our analysis in the following.

First, we assumed that the degree of gender inequality in the country of origin (observed) affects immigrants' gender role attitudes (latent), which in turn affects name giving (observed). However, we are not able to test the specific underlying motives that we have hypothesized directly. A second limitation is related to the coding of our dependent variable. We were not able to differentiate first names that are common in both the country of origin and destination. We cannot differentiate whether parents opted for such a "hybrid" first name or if they chose a name that is indeed only common in the country of destination, but not in their home country. Strictly speaking, only the latter strategy can actually be considered boundary crossing, whereas choosing a hybrid name should rather be understood as a strategy of boundary blurring. Owing to data restrictions, we had to subsume both strate- 
gies under the concept of boundary crossing. The lack of differentiation between boundary crossing and boundary blurring is a drawback of our analysis, as for some immigrants, more such "hybrid" names are available than for others because of differences in the overlap of the first name pools between the home and destination countries. However, we do not expect this problem to be linked to the gender gap in naming, which is the focus of our analysis.

A further potential drawback refers to the argument of Lieberson (2000) that the overlap in the first name pools between the countries of origin and destination may be greater for female than for male first names. If this was the case, the gender gap would rather be based on phonetic reasons than on cultural differences, such as gender role attitudes. We cannot explicitly test Lieberson's (2000) argument. However, in order to account for potential group-specific gender differences with regard to the phonetic proximity to German, we have included a control variable for the origin groups based on language similarities. We are confident that by doing so, we are able to isolate the hypothesized theoretical mechanisms from phonetic aspects.

What are the conclusions of our findings, especially in terms of their consequences for the name bearers? As shown in the introduction, several studies have indicated that there is discrimination against people with foreign names in terms of access to valuable resources (housing, employment, etc.). If daughters receive names that are common in the host society more often than sons, one may infer that girls and women are less likely to be discriminated against and, as a consequence, have better access to resources in the host country. This would be a somewhat paradoxical side effect. By giving sons names that are common in the host country more often, parents reproduce a traditional gender role model, which is characterized by a dominance of men over women. The actual effect of parents' naming choices, however, could be reversed: the integration of sons is hampered by the parents' strategy of boundary maintenance, whereas daughters can improve their position in relation to their male counterparts.

This result corresponds with findings from other studies showing that, on average, girls are more successful in the educational system than boys (Qin-Hilliard 2003; Heß-Meining 2004; Qin 2006; Zielonka et al. 2013; Abada et al. 2018; Qian et al. 2018). ${ }^{17}$ This finding is often interpreted as the result of a mismatch between the demands of the school and traditional conceptions of masculinity (Salikutluk and Heyne 2017). We suggest that a similar mechanism might be at work in name giving: again, specific conceptions of masculinity might cause parents' avoidance of boundary crossing when naming male descendants. These conceptions are first and foremost related to the intergenerational transmission of family and ethnic heritage. As a result, girls gain an integration advantage, as parents are more willing to opt for boundary crossing when they choose a female first name.

17 The magnitude of the female advantage varies between groups and is to a certain degree present in the majority population as well (Fleischmann et al. 2014). However, there seems to be a component of the female advantage that is specific to immigrants, as it is far more pronounced in some immigrant groups than in the majority population. 
Funding Deutsche Forschungsgemeinschaft, SFB 1171.

Funding Open Access funding enabled and organized by Projekt DEAL.

Open Access This article is licensed under a Creative Commons Attribution 4.0 International License, which permits use, sharing, adaptation, distribution and reproduction in any medium or format, as long as you give appropriate credit to the original author(s) and the source, provide a link to the Creative Commons licence, and indicate if changes were made. The images or other third party material in this article are included in the article's Creative Commons licence, unless indicated otherwise in a credit line to the material. If material is not included in the article's Creative Commons licence and your intended use is not permitted by statutory regulation or exceeds the permitted use, you will need to obtain permission directly from the copyright holder. To view a copy of this licence, visit http://creativecommons.org/licenses/by/4. $0 /$.

\section{Appendix}

\section{Interaction Between Gender and GDI (Interval Scaled, Z-Transformed) Derived From Logistic Regression Analyses $(N=905)$}

Fig. 2 Gender gap in the predicted probabilities of boundary crossing in name giving by GDI (z-transformed, interval scale) in the countries of origin $(N=905)$

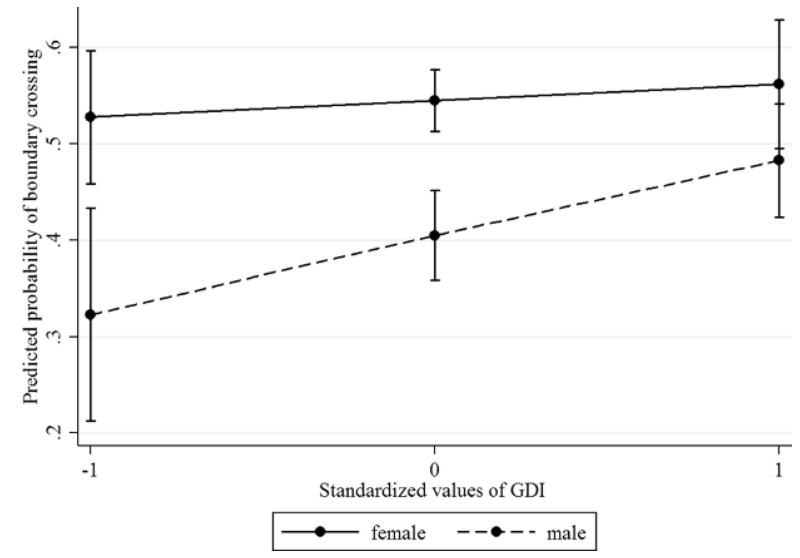




\section{Gender Differences in the Predicted Probabilities of Boundary Crossing}

Table 3 Predicted probabilities of boundary crossing in name giving for female and male descendants at different levels of the independent model variables and gender ratio in percent, $(N=905)$. (Data source: GSOEP v32, own computations)

\begin{tabular}{|c|c|c|c|}
\hline & Females & Males & Gender Ratio \\
\hline \multicolumn{4}{|l|}{ Gender Development Index } \\
\hline Low & 53.11 & 25.24 & $2.10 * *$ \\
\hline Medium & 56.89 & 43.48 & $1.31+$ \\
\hline High (ref.) & 53.53 & 49.31 & 1.08 \\
\hline \multicolumn{4}{|l|}{ Religious affiliation } \\
\hline Catholic/Protestant Christian (ref.) & 60.31 & 51.02 & 1.18 \\
\hline Orthodox Christian & 70.66 & 46.47 & $1.52+$ \\
\hline Muslim & 41.67 & 16.43 & $2.54+$ \\
\hline Other denomination & 47.43 & 21.66 & $2.19+$ \\
\hline No denomination & 42.23 & 35.43 & 1.19 n.s. \\
\hline \multicolumn{4}{|l|}{ Citizenship } \\
\hline Other citizenship (ref.) & 51.47 & 32.62 & 1.58 \\
\hline German citizenship & 58.87 & 52.58 & $1.12 *$ \\
\hline \multicolumn{4}{|l|}{ Education } \\
\hline Low (ref.) & 49.26 & 37.83 & 1.30 \\
\hline Medium & 56.44 & 42.13 & 1.34 n.s. \\
\hline High & 53.32 & 47.52 & $1.12 \mathrm{n} . \mathrm{s}$ \\
\hline \multicolumn{4}{|l|}{ Intermarriage } \\
\hline No intermarriage (ref.) & 56.37 & 44.67 & 1.26 \\
\hline German mother & 50.48 & 39.56 & 1.28 n.s. \\
\hline German father & 49.89 & 41.94 & 1.19 n.s. \\
\hline \multicolumn{4}{|l|}{ Identification with Germany } \\
\hline Weak (ref.) & 53.85 & 37.26 & 1.45 \\
\hline Medium & 56.53 & 41.74 & 1.35 n.s. \\
\hline Strong & 52.84 & 47.39 & $1.12 *$ \\
\hline
\end{tabular}

Control variables: origin group; duration of stay in Germany

Significance level of interaction effects between independent variables and gender: $+p<0.1 ; * p<0.05$; $* * p<0.01$ 


\section{Gender Gap in the Predicted Probabilities of Boundary Crossing-Alternative} Control Variable

Table 4 Predicted probabilities of boundary crossing in name giving for female and male descendants at different levels of the independent model variables and gender ratio, controlling for gender gap in the first generation instead of origin group, in percent $(N=905)$. (Data source: GSOEP v32, own computations)

\begin{tabular}{|c|c|c|c|}
\hline & Females & Males & Gender Ratio \\
\hline \multicolumn{4}{|l|}{ Gender Development Index } \\
\hline Low & 40.38 & 13.60 & $2.07 * *$ \\
\hline Medium & 64.00 & 45.40 & $1.41+$ \\
\hline High (ref.) & 64.59 & 59.40 & 1.09 \\
\hline \multicolumn{4}{|l|}{ Religious affiliation } \\
\hline Catholic/Protestant Christian (ref.) & 62.56 & 52.43 & 1.19 \\
\hline Orthodox Christian & 66.90 & 43.37 & $1.54+$ \\
\hline Muslim & 42.41 & 17.87 & $2.37+$ \\
\hline Other denomination & 44.79 & 19.88 & $2.25+$ \\
\hline No denomination & 44.07 & 36.47 & 1.21 n.s. \\
\hline \multicolumn{4}{|l|}{ Citizenship } \\
\hline Other citizenship (ref.) & 49.40 & 30.80 & 1.60 \\
\hline German citizenship & 62.57 & 54.74 & $1.14 *$ \\
\hline \multicolumn{4}{|l|}{ Education } \\
\hline Low (ref.) & 49.62 & 37.54 & 1.32 \\
\hline Medium & 56.12 & 42.45 & 1.32 n.s. \\
\hline High & 53.93 & 47.14 & 1.14 n.s. \\
\hline \multicolumn{4}{|l|}{ Intermarriage } \\
\hline No intermarriage (ref.) & 56.98 & 45.58 & 1.25 \\
\hline German mother & 48.74 & 36.85 & $1.32 \mathrm{n} . \mathrm{s}$. \\
\hline German father & 48.37 & 40.34 & 1.19 n.s. \\
\hline \multicolumn{4}{|l|}{ Identification with Germany } \\
\hline Weak (ref.) & 53.39 & 36.85 & 1.45 \\
\hline Medium & 55.63 & 41.22 & 1.35 n.s. \\
\hline Strong & 54.25 & 48.01 & $1.13 *$ \\
\hline
\end{tabular}

Control variables: gender gap in boundary crossing in the first generation of the respective origin group; duration of stay in Germany

Significance level of interaction effects between independent variables and gender: $+p<0.1 ;{ }^{*} p<0.05$; $* * p<0.01$ 


\section{References}

Abada, Teresa, Kristyn Frank and Feng Hou. 2018. Between Two Worlds: Source-Country Gender Roles and Gender Differences in Educational Attainment among Immigrant Children. Sociological Inquiry $88: 131-154$.

Alba, Richard D. 1990. Ethnic Identity. The Transformation of White America. New Haven: Yale University Press.

Alba, Richard D., and Victor Nee. 2005. Remaking the American mainstream. Assimilation and contemporary immigration. Cambridge, Mass.: Harvard University Press.

Alexander, Amy C., and Christian Welzel. 2011. Islam and patriarchy: how robust is Muslim support for patriarchal values? International Review of Sociology 21:249-276.

Alford, Richard D. 1987. Naming and identity. A cross-cultural study of personal naming practices. New Haven, Conneticut: H R A Flex Books.

Auspurg, Katrin, Thomas Hinz and Laura Schmid. 2017. Contexts and conditions of ethnic discrimination: Evidence from a field experiment in a German housing market. Journal of Housing Economics $35: 26-36$.

Becher, Inna, and Yasemin El-Menouar. 2014. Geschlechterrollen bei Deutschen und Zuwanderern christlicher und muslimischer Religionszugehörigkeit. Forschungsbericht No. 21. Nürnberg.

Becker, Birgit. 2009. Immigrants' emotional identification with the host society. Ethnicities 9:200-225.

Becker, Rolf. 2011. Integration von Migranten durch Bildung und Ausbildung - theoretische Erklärungen und empirische Befunde. In Integration durch Bildung, ed. Rolf Becker, 11-36. Wiesbaden: VS Verlag für Sozialwissenschaften.

Bertrand, Marianne, and Sendhil Mullainathan. 2004. Are Emily and Greg More Employable Than Lakisha and Jamal? A Field Experiment on Labor Market Discrimination. American Economic Review 94:991-1013.

Blommaert, Lieselotte, Marcel Coenders and Frank van Tubergen. 2014. Discrimination of Arabic-Named Applicants in the Netherlands. An Internet-Based Field Experiment Examining Different Phases in Online Recruitment Procedures. Social Forces 92:957-982.

Chiswick, Barry R. 1991. Speaking, Reading, and Earnings among Low-Skilled Immigrants. Journal of Labor Economics 9:149-170.

Dorbritz, Jürgen. 2017. Die demografischen Transformationen und das ungelöste Genderproblem. In Die transformative Macht der Demografie, ed. Tilman Mayer, 75-89. Wiesbaden: Springer Fachmedien Wiesbaden; Imprint: Springer VS.

Esser, Hartmut. 2001. Integration und ethnische Schichtung. Arbeitspapier No. 40. Mannheim: Mannheimer Zentrum für Europäische Sozialforschung.

Feliciano, Cynthia, and Rubén G. Rumbaut. 2005. Gendered paths: Educational and occupational expectations and outcomes among adult children of immigrants. Ethnic and Racial Studies 28:1087-1118.

Fick, Patrick. 2016. Does Naturalization Facilitate Integration? A Longitudinal Study on the Consequences of Citizenship Acquisition for Immigrants' Identification with Germany. Zeitschrift für Soziologie 45.

Fish, M. Steven. 2002. Islam and Authoritarianism. World Politics 55:4-37.

Fleischmann, Fenella, Cornelia Kristen, Anthony F. Heath, Yaël Brinbaum, Patrick Deboosere, Nadia Granato, Jan O. Jonsson, Elina Kilpi-Jakonen, Georg Lorenz, Amy C. Lutz, David Mos, Raya Mutarrak, Karen Phalet, Catherine Rothon, Frida Rudolphi and Herman G. van de Werfhorst. 2014. Gender Inequalities in the Education of the Second Generation in Western Countries. Sociology of Education 87:143-170.

Friedberg, Rachel M. 2000. You Can't Take It with You? Immigrant Assimilation and the Portability of Human Capital. Journal of Labor Economics 18:221-251.

Fryer, Roland G., and Steven D. Levitt. 2004. The Causes and Consequences of Distinctively Black Names. The Quarterly Journal of Economics 119:767-805.

Gerhards, Jürgen, and Silke Hans. 2009. From Hasan to Herbert. Name-Giving Patterns of Immigrant Parents between Acculturation and Ethnic Maintenance. American Journal of Sociology 114:1102-1128.

Gerhards, Jürgen, Mike S. Schäfer and Sylvia Kämpfer. 2009. Gender Equality in the European Union: The EU Script and its Support by European Citizens. Sociology 43:515-534.

Goebel, Jan, Markus M. Grabka, Stefan Liebig, Martin Kroh, David Richter, Carsten Schröder and Jürgen Schupp. 2019. The German Socio-Economic Panel (SOEP). Jahrbücher für Nationalökonomie und Statistik 239(2):345-360.

Gordon, Milton Myron. 1964. Assimilation in American life. The Role of Race, Religion, and National Origins. New York: Oxford University Press. 
Haug, Sonja. 2003. Interethnische Freundschaftsbeziehungen und soziale Integration. Kölner Zeitschrift für Soziologie und Sozialpsychologie 55:716-736.

Haug, Sonja, and Sonja Pointner. 2007. Soziale Netzwerke, Migration und Integration. In Sozialkapital. Grundlagen und Anwendungen. Kölner Zeitschrift für Soziologie und Sozialpsychologie Sonderheft, vol. 47, eds. Axel Franzen and Markus Freitag, 367-396. Wiesbaden: VS Verlag für Sozialwissenschaften.

Herbert, Robert K. 1999. Personal Names as Social Protest: The Status of African Political Names. Names 47:109-124.

Heß-Meining, Ulrike. 2004. Geschlechterdifferenzen in der Bildungssituation von Migrantlnnen. In Migration, Ethnie und Geschlecht, eds. Iris Bednarz-Braun and Ulrike Heß-Meining, 133-174. Wiesbaden: VS Verlag für Sozialwissenschaften.

Horowitz, Donald L. 1975. Ethnic Identity. In Ethnicity: Theory and Experience, eds. Nathan Glazer, Daniel P. Moynihan and Corinne S. Schelling, 111-140. Cambridge, Mass.: Harvard University Press.

Horr, Andreas, Christian Hunkler and Clemens Kroneberg. 2018. Ethnic Discrimination in the German Housing Market. A Field Experiment on the Underlying Mechanisms. Zeitschrift für Soziologie 47:134-146.

Howard, Marc M. 2003. Foreigners or Citizens? Citizenship policies in the countries of the EU [paper prepared for the European Union Studies Association conference, March 27-29, 2003].

Humpert, Andreas, and Klaus Schneiderheinze. 2000. Stichprobenziehung für telefonische Zuwandererumfragen: Einsatzmöglichkeiten der Namenforschung. ZUMA Nachrichten 24:36-63.

Inglehart, Ronald, and Pippa Norris. 2003. Rising Tide. Gender Equality and Cultural Change Around the World. Cambridge: Cambridge Univ. Press.

Kaas, Leo, and Christian Manger. 2012. Ethnic Discrimination in Germany's Labour Market: A Field Experiment. German Economic Review 13:1-20.

Lamont, Michèle, and Christopher Bail. 2008. Bridging Boundaries: The Equalization Strategies of Stigmatized Ethno-racial Groups Compared. Center for European Studies Working Paper Series No. 154.

Lieberson, Stanley. 2000. A Matter of Taste: How Names, Fashions, and Culture Change. New Haven, Connecticut: Yale University Press.

Lieberson, Stanley, and Kelly S. Mikelson. 1995. Distinctive African American Names. An Experimental, Historical, and Linguistic Analysis of Innovation. American Sociological Review 60:928-946.

Lieberson, Stanley, Susan Dumais and Shyon Baumann. 2000. The Instability of Androgynous Names. The Symbolic Maintenance of Gender Boundaries. American Journal of Sociology 105:1249-1287.

Luthra, Renee, Roger Waldinger and Thomas Soehl. 2018. Origins and Destinations. The Making of the Second Generation. Chicago: Russell Sage Foundation.

Moghadam, Valentine M. 2003. Modernizing women. Gender and social change in the Middle East. 2nd ed. Boulder, Colo: L. Rienner.

Norris, Pippa, and Ronald Inglehart. 2002. Islam \& the West: Testing the Clash of Civilizations Thesis. John F. Kennedy School of Government Harvard University Faculty Research Working Papers Series RWP02-015.

Qian, Yue, Claudia Buchmann and Zhe Zhang. 2018. Gender differences in educational adaptation of immigrant-origin youth in the United States. Demographic Research 38:1155-1188.

Qin, Desiree B. 2006. The Role of Gender in Immigrant Children's Educational Adaptation. Current Issues in Comparative Education 9:8-19.

Qin-Hilliard, Desirée B. 2003. Gendered expectations and gendered experiences: immigrant students' adaptation in schools. New directions for youth development 100:91-109.

Ross, Michael L. 2008. Oil, Islam, and Women. American Political Science Review 102:107-123.

Rumbaut, Ruben G. 1994. The Crucible Within: Ethnic Identity, Self-Esteem, and Segmented Assimilation among Children of Immigrants. International Migration Review 28:748-794.

Salikutluk, Zerrin, and Stefanie Heyne. 2017. Do Gender Roles and Norms Affect Performance in Maths? The Impact of Adolescents' and their Peers' Gender Conceptions on Maths Grades. European Sociological Review 33:368-381.

Schneider, Jan, Ruta Yemane and Martin Weinmann. 2014. Diskriminierung am Ausbildungsmarkt: Ausmaß, Ursachen und Handlungsperspektiven. Sachverständigenrat deutscher Stiftungen für Integration und Migration. Berlin: Sachverständigenrat deutscher Stiftungen für Integration und Migration.

Skrobanek, Jan. 2009. Perceived Discrimination, Ethnic Identity and the (Re-) Ethnicisation of Youth with a Turkish Ethnic Background in Germany. Journal of Ethnic and Migration Studies 35:535-554.

Steinmann, Jan-Philip. 2018. The paradox of integration: why do higher educated new immigrants perceive more discrimination in Germany? Journal of Ethnic and Migration Studies 945:1-24. 
Sue, Christina A., and Edward E. Telles. 2007. Assimilation and Gender in Naming. American Journal of Sociology 112:1383-1415.

Watkins, Susan C., and Andrew S. London. 1994. Personal Names and Cultural Change: A Study of the Naming Patterns of Italians and Jews in the United States in 1910. Social Science History 18:169-209.

Widner, Daniel, and Stephen Chicoine. 2011. It's All in the Name: Employment Discrimination Against Arab Americans. Sociological Forum 26:806-823.

Wimmer, Andreas. 2008. Elementary strategies of ethnic boundary making. Ethnic and Racial Studies 31:1025-1055.

Wood, Nichola, and Louise Waite. 2011. Editorial: Scales of belonging. Emotion, Space and Society 4:201-202.

Zielonka, Markus, Ilona Relikowski, Lydia Kleine, Nicole Luplow, Erbil Yilmaz, Thorsten Schneider and Hans-Peter Blossfeld. 2013. Migrations- und geschlechtsspezifische Disparitäten in der Primarund Sekundarstufe. Befunde aus der Längsschnittstudie BiKS-8-14. In Geschlecht, Migrationshintergrund und Bildungserfolg, eds. Andreas Hadjar and Sandra Hupka-Brunner, 133-158. Weinheim, Basel: Beltz Juventa.

Zolberg, Astride R., and Long L. Woon. 1999. Why Islam is like Spanish: Cultural Incorporation in Europe and the United States. Politics \& Society 27:5-38.

Jürgen Gerhards 1955. Dr. phil., Professor of Macrosociology, Freie Universität Berlin. Main areas of research: comparative cultural sociology, European studies, sociology of the public sphere. Recent publications: How strong is European solidarity? Insights from a thirteen-country survey. London 2019 (with H. Lengfeld, Z.S. Ignácz, F.K. Kley and M. Priem); Social class and transnational human capital. How upper and middle class parents prepare their children for globalization. London 2017 (with S. Hans u. S. Carlson).

Julia Tuppat 1986. Dr. phil., research assistant at the Institute of Sociology, Freie Universität Berlin. Main areas of research: social inequality, education, health, migration and integration. Recent publication: Reversing the symbolic order of discrimination: results from a field experiment on the discrimination of migrants and transgender people in theatre. Journal of Ethnic and Migration Studies, 2020 (with J. Gerhards and T. Sawert). 